\title{
Efficient Removal of Micropollutants in Rainwater by New Vacuum Ultraviolet
}

\author{
Zheng $\mathrm{Li}^{\mathrm{a}, \star}$, Weipeng Chen ${ }^{\mathrm{b}}$, Siyang Yue ${ }^{\mathrm{c}}$ \\ Suzhou Industrial Park Design \& Research Institute CO., LTD, Suzhou 215027, China. \\ alizheng@sipdri.com, ${ }^{b}$ chenweipeng@sipdri.com, cyuesiyang@126.com
}

\begin{abstract}
Keywords: Vacuum UV (VUV), Rainwater, Micropollutants, Advanced oxidation processes
\end{abstract} Abstract. Toxic micropollutants in rainwater challenge the effective reuse of rainwater. This study proposed the application of newly developed vacuum-ultraviolet (VUV) in the advanced treatment of rainwater, and assessed the efficiency and feasibility in application. The VUV was generated from the UV lamp made of the new special silica. Benzoic acid, p-hydroxyl benzoic acid, bisphenol A, p-chlorobenzoic acid, nitrobenzene, and p-chloronitrobenzene were selected as target compounds. Their degradation efficiency was evaluated, and the degradation kinetics were also analyzed. Influence of $\mathrm{pH}$ was investigated, and the degradation mechanisms were explored by distinguishing the individual contributions of different radicals involved. The efficiency of VUV was further compared with that of $\mathrm{H}_{2} \mathrm{O}_{2} / \mathrm{UV}$ process, and its advantages were consequently discussed when applied in the practical rainwater treatment. The results obtained here will support the VUV irradiation as an promising treatment process for the purification of rainwater for the centralized and decentralized systems to guarantee the safety of the rainwater reuse.

\section{Introduction}

Our world suffers from an increasing water crisis because of the climate change, anthropogenic water pollution [1-4]. Besides stringent wastewater treatment prior to drainage to environment and development of new and effective water treatment methods to guarantee the safety of water use, exploration and full utilization of new water resources are promising [1, 5]. From the point of view of water circulation globally, in essence, rainwater or storm water is the origin of fresh water. So rainwater harvesting and utilization is a promising approach to alleviate the water crisis [6-10].

Rainwater can be used for many purposes, such as irrigation in agriculture, landscape, toilet flushing, firefighting, and even drinking water. Because the pollutants released from industrial factories, traffic, etc. in various areas to atmosphere, inorganic ions and especially the toxic organics (e.g., nitrobenzene and phenols) exist in the rainwater all over the world, in addition to the micro and macro particles and microbes [11-14]. Most of those toxic organic pollutants are volatile and even recalcitrant, and thus they indeed challenge rainwater utilization. Hence, advanced purification of rainwater is central to guarantee the safety of its wide utilization.

Most of the current strategies including coagulation, membrane filtration, adsorption, biodegradation, oxidation, and chlorine and UV disinfection are limited to some extent in practical application and should be selected and applied case on case [15]. The rainwater is usually unevenly distributed globally and annually. Furthermore, the rainwater compositions are also dependent upon the location-specific chemicals released there. Different purpose of rainwater utilization also needs special treatment highly depending on the costs. Advanced oxidation processes (AOPs) are attractive for the generation of very powerfully oxidizing species hydroxyl radical, $\mathrm{HO} \bullet$, which can efficiently destruct and even mineralize most of the organics to $\mathrm{CO}_{2}$ [16-18]. Vacuum-UV (VUV) irradiation is a recently emerging method, which also generates $\mathrm{HO} \cdot$ efficiently by the photoionization of water molecules after absorbing photons having short wavelength, e.g., $185 \mathrm{~nm}[19,20]$. The most important is no requirement of addition of extra oxidants and thus subsequent removal of residual chemicals. Hence, it is relatively a green technique for water treatment. However, there has been no report on its removal of micropollutants in rainwater. 
Therefore, the objectives of this study was to investigate the efficiency of VUV on removal of organic micropollutants in rainwater and to evaluate the feasibility in potential practical application. Benzoic acid (BA), p-hydroxyl benzoic acid (pHBA), bisphenol A (BPA), p-chlorobenzoic acid (pCBA), nitrobenzene (NB), and p-chloronitrobenzene (pCNB), representing micropollutants possessing different properties, were selected as the target compounds.

\section{Materials and Methods}

Materials. BA, pHBA, BPA, pCBA, NB, and pCNB were of ACS reagent grade and were from Sigma-Aldrich. Phosphoric acid and methanol of HLPC grade were purchased from Tedia. Other reagents were of analytical-reagent grade and purchased from Sinopharm Chemical Reagent Co., Ltd. All the chemicals were used as received without further purification, and all solutions were prepared in 18.2 $\mathrm{M} \Omega \bullet \mathrm{cm}^{-1}$ Milli-Q water produced from a Milli-Q Biocel water system.

The rainwater samples were collected from a rainfall event in a metropolis located in the east of China, in June, 2015. The rainwater samples were filtered using $0.45 \mu \mathrm{m}$ cellulose membrane and were stored at $4{ }^{\circ} \mathrm{C}$ prior to use. The rainwater quality were as follows: suspend solid $8.1 \pm 0.1 \mathrm{mg} / \mathrm{L}, \mathrm{COD}$ $30.5 \pm 2.1 \mathrm{mg} / \mathrm{L}, \mathrm{pH} 5.8 \pm 0.2$, TOC $7.3 \pm 0.2 \mathrm{mg} / \mathrm{L}, \mathrm{UV}_{254} 0.052 \pm 0.001 \mathrm{~cm}^{-1}, \mathrm{NH}_{3}-\mathrm{N} 1.05 \pm 0.04$ $\mathrm{mg} / \mathrm{L}, \mathrm{NO}_{3}-\mathrm{N} 3.81 \pm 0.22 \mathrm{mg} / \mathrm{L}, \mathrm{TP} 0.11 \pm 0.01 \mathrm{mg} / \mathrm{L}, \mathrm{Cl}^{-} 1.12 \pm 0.03 \mathrm{mg} / \mathrm{L}, \mathrm{SO}_{4}{ }^{2-} 33.62 \pm 0.61 \mathrm{mg} / \mathrm{L}$, and total phenol $0.03 \mu \mathrm{M}$, respectively. Target compounds were spiked into the rainwater prior experiments. Solution $\mathrm{pH}$ was adjusted by $1 \mathrm{mM}$ of $\mathrm{HCl}$ or $\mathrm{NaOH}$ solutions when necessary.

Procedures. All the photolysis experiments were performed in a cylindrical photoreactor, with a 10 W low-pressure mercury UV lamp centered in the cylindrical vessel axially. A tank $(2.0 \mathrm{~L})$ was attached to the reactor and the solution was circulated between the photoreactor and the tank by a pump. The UV lamp and sleeve outside were made of special silica that can permit the transmission of low wavelength of VUV light at $185 \mathrm{~nm}$ with high efficiency. Experiments were carried out at ambient temperature $\left(22 \pm 2{ }^{\circ} \mathrm{C}\right)$. Samples were quenched using excessive sodium thiosulfate if necessary. All experiments were repeated at least two times, and average values along with one standard deviation are presented.

Analytical Methods. The target compounds were analyzed on a high performance liquid chromatography (Waters 2695 HPLC) equipped with a 2489 UV Detector and a autosampler, using a Waters symmetry C18 column $(4.6 \mathrm{~mm} \times 150 \mathrm{~mm}, 5 \mu \mathrm{m})$ and C18 guard column for separation. An eluent of phosphate buffer ( $\mathrm{pH} 3)$ and methanol (20:80 50:50, v/v \%) was used at a flow rate of 1.0 $\mathrm{ml} / \mathrm{min}$. The concentration of BA, pHBA, pCBA, BPA, NB, and pCNB was quantified at $227 \mathrm{~nm}, 254$ $\mathrm{nm}, 234 \mathrm{~nm}, 280 \mathrm{~nm}, 263 \mathrm{~nm}$ and $250 \mathrm{~nm}$, respectively. The $\mathrm{pH}$ values were measured by a $\mathrm{pH}$ meter (PB-10, Satorious). The UV absorption was carried out on a spectrophotometer (UV-2550, Shimadzu). The cations and anions were analyzed on an ion chromatograph (ICS-3000, Dionex). TOC and TN were analyzed by a TOC analyzer (TOCL, Shimadzu). All the other analysis not mentioned above was carried out according to the standard methods [21].

\section{Results and Discussion.}

\section{Degradation of several typical micropollutants by VUV.}

The rainwater quality indicated the pollution of micropollutants according to $\mathrm{UV}_{254}, \mathrm{TOC}$, and total phenols. In order to assess the efficiency of VUV and its feasibility in the removal of organic micropollutants, $\mathrm{BA}, \mathrm{pHBA}, \mathrm{BPA}, \mathrm{pCBA}, \mathrm{NB}$, and $\mathrm{pCNB}$, were selected as the target compounds. pHBA and BPA are phenols and represent the phenols in the rainwater. $\mathrm{NB}$ and $\mathrm{pCNB}$ are the representative of volatile and refractory aromatic pollutants in the rainwater, and they could be released from the exhaust gas of traffic or chemical industry factory. BA and pCBA are organic aromatic acids that are also refractory, and were selected on the consideration of their formation from the transformation of aromatics in the atmosphere [14].

Fig. 1 shows the removal efficiency of the six compounds in the rainwater by the VUV method. All the compounds in the rainwater underwent rapid degradation by VUV and more than $70 \%$ was 
removed within 5 min. NB shows the lowest removal efficiency in the process, while BPA the best. It is noted that the initial concentration of BPA was $5 \mu \mathrm{M}$ while the others were $10 \mu \mathrm{M}$. Actually, all the compounds were almost completely removed within $10 \mathrm{~min}$ in the process (data not given), suggesting the high efficiency of VUV.

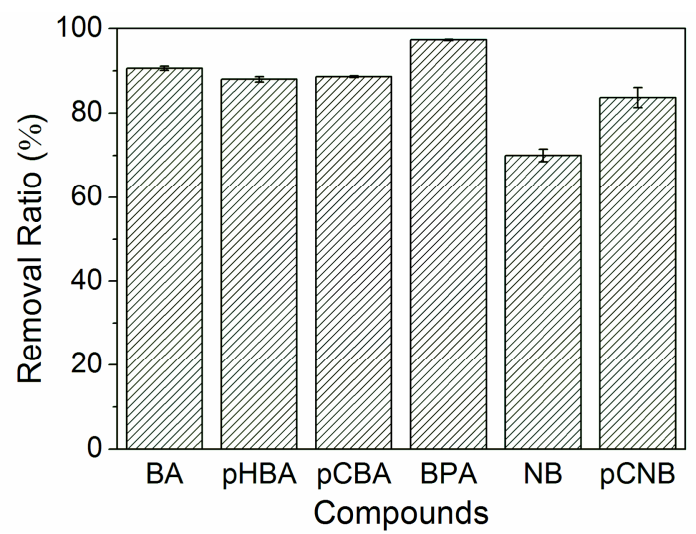

Fig. 1 Degradation of the six aromatic compounds in VUV process. Conditions: $C_{0}=10 \mu \mathrm{M},[\mathrm{BPA}]_{0}$ $=5 \mu \mathrm{M}, \mathrm{pH} 5.8,22 \pm 2{ }^{\circ} \mathrm{C}$, and time of $5 \mathrm{~min}$.

\section{Degradation kinetics.}

Fig. 2 shows the degradation kinetics of the selected compounds in the VUV process. Clearly, all the degradation agreed well with the pseudo-first-order kinetics, and the fit statistics are summarized in the Table 1. BA, pHBA, and pCBA shared a similar kinetic rate constant. NB had the lowest rate constant, while BPA had the highest one, possibly due to its lower initial concentration and higher reactivity towards reactive species [22]. Thus, Fig. 2 and Table 1 clearly showed and compared the efficiency of VUV on the removal of different pollutants kinetically.

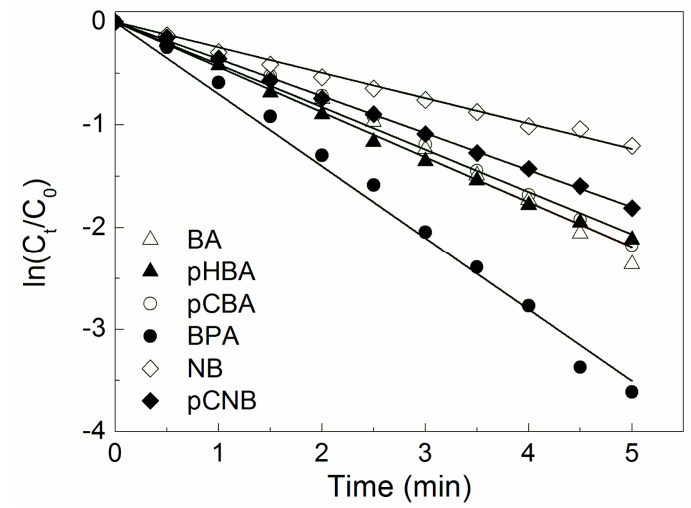

Fig. 2 Degradation kinetics of the six aromatic compounds in VUV process. The lines represent the best linear fits. Conditions: $C_{0}=10 \mu \mathrm{M},[\mathrm{BPA}]_{0}=5 \mu \mathrm{M}, \mathrm{pH} \mathrm{5.8}$, and $22 \pm 2{ }^{\circ} \mathrm{C}$.

Table 1. Fit statistics of the pseudo-order-kinetics fitting.

\begin{tabular}{lll}
\hline & $k\left[\mathrm{~min}^{-1}\right]$ & $R^{2}$ \\
\hline BA & $0.4371 \pm 0.0105$ & 0.9942 \\
pHBA & $0.4384 \pm 0.004$ & 0.9992 \\
pCBA & $0.4134 \pm 0.0082$ & 0.9961 \\
BPA & $0.7007 \pm 0.01238$ & 0.9969 \\
NB & $0.2469 \pm 0.00376$ & 0.9977 \\
pCNB & $0.3602 \pm 0.00186$ & 0.9997 \\
\hline
\end{tabular}

\section{Effect of pH.}

In order to evaluate the feasibility of VUV in application of micropollutants removal in rainwater treatment, influence of $\mathrm{pH}$ was studied. Considering its stability, pCBA was selected as the probe compound, which was also widely used to assess the oxidation efficiency of AOPs [23].

Fig. 3 shows the influence of $\mathrm{pH}$ on the removal of $\mathrm{pCBA}$ by VUV. About equal removal efficiency at $\mathrm{pH} 3, \mathrm{pH} 7$, and $\mathrm{pH} 9$ were obtained and no significant influence of $\mathrm{pH}$ was observed. Considering 
the wide range of $\mathrm{pH}$ of the rainwater all over the world $[24,25]$, hence, it is indeed the advantage of VUV that its removal efficiency on micropollutants was not affected by $\mathrm{pH}$.

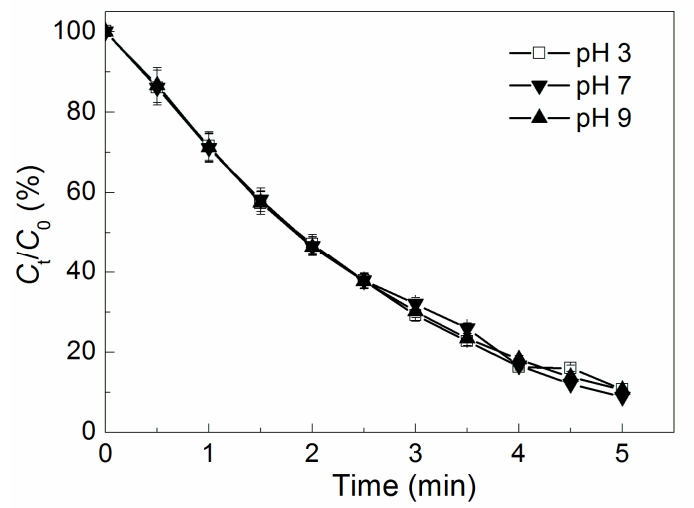

Fig. 3 pCBA degradation in VUV process at various pHs. Conditions: $C_{0}=10 \mu \mathrm{M}$, and $22 \pm 2{ }^{\circ} \mathrm{C}$.

\section{Efficiency comparison.}

The green process, $\mathrm{H}_{2} \mathrm{O}_{2} / \mathrm{UV}$, is a classical and widely used AOP in water treatment [26]. Then the comparison of efficiency between VUV and $\mathrm{H}_{2} \mathrm{O}_{2} / \mathrm{UV}$ was carried out, with results shown in Fig. 4. It is note that the UV lamp emitting only UV light at $254 \mathrm{~nm}$ was used in the $\mathrm{H}_{2} \mathrm{O}_{2} / \mathrm{UV}$ process. From Fig. 4, $\mathrm{H}_{2} \mathrm{O}_{2} / \mathrm{UV}$ showed higher efficiency than VUV on pCBA degradation. However, about $1 \mathrm{mM} \mathrm{H}_{2} \mathrm{O}_{2}$ was used in the $\mathrm{H}_{2} \mathrm{O}_{2} / \mathrm{UV}$, which required the necessarily subsequent treatment of residual $\mathrm{H}_{2} \mathrm{O}_{2}$. In comparison, VUV didn't need any chemicals, but also achieved the high oxidation efficiency. Considering the purpose of rainwater utilization, such as washing and even drinking, hence, VUV seems to be much greener and safer, and is a much better choice instead of $\mathrm{H}_{2} \mathrm{O}_{2} / \mathrm{UV}$ process for the micropollutants treatment from rainwater.

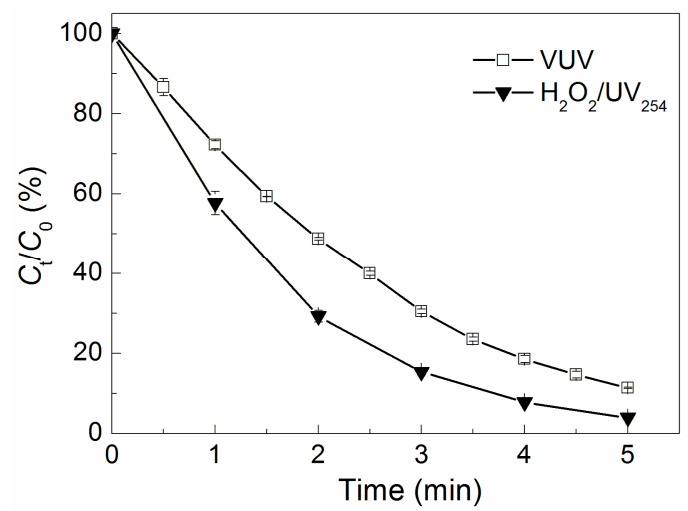

Fig. 4 Degradation of pCBA by VUV and $\mathrm{H}_{2} \mathrm{O}_{2} / \mathrm{UV}$ processes. Conditions: $\mathrm{C}_{0}=10 \mu \mathrm{M},\left[\mathrm{H}_{2} \mathrm{O}_{2}\right]_{0}=1$ $\mathrm{mM}, \mathrm{pH} \mathrm{5.8}$, and $22 \pm 2{ }^{\circ} \mathrm{C}$.

\section{Mechanism.}

It has been reported that reactive species such as $\mathrm{HO} \bullet$ can be generated during the photolysis of water molecule, which absorbs VUV light photon, following the reaction Eq 1 [19, 20, 27]. Then many other oxidizing and reducing reactive species, e.g., $\mathrm{H}_{2} \mathrm{O}_{2}$ and $\mathrm{O}_{2}{ }^{--}$would be formed via radical recombination reactions or derivation [19]. In the presence of dissolved oxygen, reducing species would be captured by oxygen to produce other less reactive species participating in other radical reactions or oxidation of intermediates. In order to explore the mechanism of the micropollutants removal in the VUV system, inhabitation effect of methanol on the removal of pCBA was performed, with the results in Fig. 5. From Fig. 5, it can be seen that $10 \mathrm{mM}$ methanol dramatically inhibited the pCBA degradation in VUV, suggesting the great involvement of $\mathrm{HO} \bullet$ in the oxidation of pCBA. However, even the much excess methanol failed to completely inhibit the pCBA degradation, which was still more rapid than the direct photolysis of pCBA under the UV irradiation at $254 \mathrm{~nm}$ sharing about the same UV intensity according to the manufacturer. Hence, there must be some other species that made contributions to the pCBA 
degradation, and the possible species involved were regarded to be superoxide radical, such as $\mathrm{HO}_{2} \bullet$ or $\mathrm{O}_{2}{ }^{\circ}$. Fig. 5 also supports that $\mathrm{HO} \bullet$ contributed most to the pCBA degradation in the VUV system.

$$
\mathrm{H}_{2} \mathrm{O}+h v \rightarrow \mathrm{HO} \bullet+\mathrm{H} \bullet+\mathrm{e}_{\mathrm{aq}}{ }^{-}+\mathrm{H}^{+}
$$

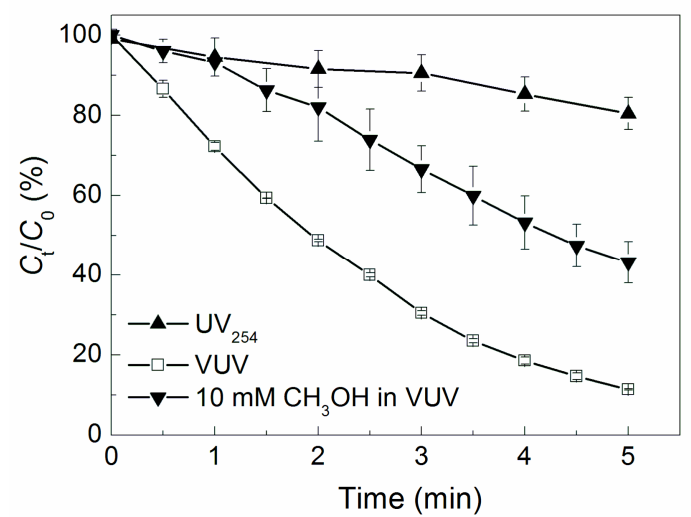

Fig. 5 Inhibition effect of methanol on pCBA degradation in VUV process. Conditions: $\mathrm{C}_{0}=10 \mu \mathrm{M}$, $\mathrm{pH} 5.8$, and $22 \pm 2{ }^{\circ} \mathrm{C}$.

The recent development of VUV light sources has admitted the in situ generation of hydroxyl radicals and other reactive species, and it is much advantageous over AOPs on the no requirement of oxidants addition, subsequent removal of residual chemicals [20]. Several studies have also shown a fast degradation of organic micropollutants using the irradiation of water by VUV light, and this study assessed the efficiency and feasibility in rainwater treatment $[19,20]$. Another important advantage of VUV is the efficient and simultaneous disinfection of rainwater, without requiring addition of extra disinfectants. Therefore, VUV irradiation offers the new possibilities for special applications like the purification of rainwater as an promising treatment process for centralized in urban locations and decentralized systems such as in buildings and artificial turf.

\section{Conclusions:}

(1) The VUV process showed high efficiency on removal of six types of micropollutants including phenols and recalcitrant aromatics in the rainwater. All the degradation of those target compounds by VUV obeyed the pseudo-first-order kinetics, and shared similar rate constants.

(2) Solution $\mathrm{pH}$ didn't affect the oxidation efficiency of VUV.

(3) Mechanism study indicated that hydroxyl radical made the most contribution to pCBA removal, and other species like super oxides radicals should also participated in its removal.

(4) Compared with the $\mathrm{H} 2 \mathrm{O} 2 / \mathrm{UV}$ process, although the VUV process had a little lower oxidation efficiency, it was much advantageous on no requirement of oxidants and subsequent removal of residual chemicals. The VUV process would be promising in advanced treatment of rainwater for its high efficiency, easy installation, and simple operation and management, to guarantee the safety of the rainwater reuse.

\section{Acknowledgements:}

This work was supported by the Jiangsu provincial science and technology support program (No. SF06).

\section{References:}

[1] S.R. Carpenter, E.H. Stanley, M.J. Vander Zanden: Annu. Rev. Environ. Resour. 36 (2011) 75-99.

[2] J. Bohannon: Science 313 (2006) 1085-1087. 
[3] R.P. Schwarzenbach, T. Egli, T.B. Hofstetter, U. von Gunten, B. Wehrli: Annu. Rev. Environ. Resour. 35 (2010) 109-136.

[4] E.M. Fischer, R. Knutti: Nature Clim. Change 5 (2015) 560-564.

[5] G.W.H. Simons, W.G.M. Bastiaanssen, W.W. Immerzeel: J. Hyd 522 (2015) 558-571.

[6] A.S. Vieira, C.D. Beal, E. Ghisi, R.A. Stewart: Renewable and Sustainable Energy Reviews 34 (2014) 225-242.

[7] B. Blocken, D. Derome, J. Carmeliet: Build. Environ. 60 (2013) 339-361.

[8] S. Ward, F.A. Memon, D. Butler: Water Res. 46 (2012) 5127-5134.

[9] S. Ward, S. Barr, F. Memon, D. Butler: Urban Water Journal 10 (2012) 112-126.

[10] V. Naddeo, D. Scannapieco, V. Belgiorno: J. Hyd 498 (2013) 287-291.

[11]R. Huston, Y.C. Chan, T. Gardner, G. Shaw, H. Chapman: Water Res. 43 (2009) 1630-1640.

[12]H.-W. Xiao, H.-Y. Xiao, A.-M. Long, Y.-L. Wang, C.-Q. Liu: J. At. C 70 (2013) 269-281.

[13]H. Niu, Y. He, X.X. Lu, J. Shen, J. Du, T. Zhang, T. Pu, H. Xin, L. Chang: Atm. Re. 144 (2014) 195-206.

[14]M.A.J. Harrison, S. Barra, D. Borghesi, D. Vione, C. Arsene, R. Iulian Olariu: Atmos. Environ. 39 (2005) 231-248.

[15]M. Elimelech, W.A. Phillip: Science 333 (2011) 712-717.

[16]M.B. Heeb, J. Criquet, S.G. Zimmermann-Steffens, U. von Gunten: Water Res. 48 (2014) 15-42.

[17]I.A. Katsoyiannis, S. Canonica, U. von Gunten: Water Res. 45 (2011) 3811-3822.

[18]C. Liu, U. von Gunten, J.-P. Croué: Water Res. 47 (2013) 5307-5315.

[19]M.G. Gonzalez, E. Oliveros, M. Worner, A.M. Braun: J. Photochem. Photobiol., C 5 (2004) 225-246.

[20]K. Zoschke, H. Börnick, E. Worch: Water Res. 52 (2014) 131-145.

[21]A.P.H. Association, Awwa, W.E. Federation, Standard Methods for the Examination of Water and Wastewater. 22 edition ed.; American Water Works Assn: Washington, DC, 2012; p 1496.

[22] G.V. Buxton, C.L. Greenstock, W.P. Helman, A.B. Ross: Phys. Chem. Ref. Data 17 (1988) 513-886.

[23]Y. Lee, U. von Gunten: Water Res. 44 (2010) 555-566.

[24]K. Vijayaraghavan, U.M. Joshi, R. Balasubramanian: Water Res. 46 (2012) 1337-1345.

[25]A. Gioda, O.L. Mayol-Bracero, F.N. Scatena, K.C. Weathers, V.L. Mateus, W.H. McDowell: Atmos. Environ. 68 (2013) 208-220.

[26] J.C. Crittenden, S. Hu, D.W. Hand, S.A. Green: Water Res. 33 (1999) 2315-2328.

[27]F. Crapulli, D. Santoro, M.R. Sasges, A.K. Ray: Water Res. 64 (2014) 209-225. 